\title{
| O Enfermeiro como Ser Sócio-Político: refletindo a visibilidade da profissão do cuidado
}

\author{
The Nurse as a Social and Political Being: critical analysis of nursing as a caring profession \\ El enfermero como ser sociopolítico: reflexionando la visibilidad de la profesión del cuidado
}

\author{
Daiane Dal Pai ${ }^{1}$, Guisela Schrank ${ }^{2}$, Eva Neri Rubim Pedro ${ }^{3}$
}

\section{RESUMO}

Pretende-se, com este trabalho, instigar o profissional de enfermagem a repensar seu fazer, saber e ser. Trata-se de uma reflexão crítica quanto ao cuidado dispensado à profissão do cuidado. Acredita-se que este deva iniciar com a busca, ocupação ou conhecimento, de um espaço sóciopolítico que possibilite a conquista de prestígio às competências adquiridas numa prática social de envolvimento íntimo com o indivíduo, sociedade e ambiente. Com base na construção dos saberes de enfermagem, historicamente determinados pelas necessidades compreendidas pela inserção social no campo da saúde, consideram-se os padrões de conhecimento fundamentais em enfermagem, bem como, o campo de atuação e o espaço social da profissão, para apontar considerações relevantes sobre a formação do ser sócio-político. Contudo, há, de fato, espaço para o profissional neste campo de atuação? Defende-se aqui, a necessidade de ocupar espaços que dêem margem ao reconhecimento da enfermagem como protagonista da práxis em saúde e na sociedade.

Descritores: Enfermagem; Conhecimento; Política.

\begin{abstract}
The purpose of this study was to investigate professional nurses regarding their competency of doing, knowing, and being. This was a critical analysis study about nursing as a caring profession. It is believed that professional nurses should look for a social and political place that allows them to achieve recognition for their skills, knowledge, and competencies. This will allow nurses to conquer prestige for their social practice through close interaction with the individual, the society, and the environment. Professional nursing knowledge has historically been determined by societal needs. The body of knowledge must be examined in the context of the nursing patterns of knowing and in the context of the social and political place of nursing. However, is there a place for nurses in the social and political arena? Here is a discussion of the need of nurses to occupy a social and political place that grants recognition to the nursing profession as the protist of the praxis in health and society.
\end{abstract}

Keywords: Nursing; Knowlegde; Politics.

\section{RESUMEN}

Con este trabajo se pretende instigar al personal de enfermería a repensar en su hacer, saber, y ser. Se trata de una reflexión crítica sobre el cuidado dispensado a la profesión del cuidado. Se cree que este deba iniciarse con la búsqueda, ocupación o conocimiento, de un espacio sociopolítico que posibilite la conquista del prestigio a las competencias adquiridas en una práctica social de envolvimiento íntimo con el individuo, sociedad y ambiente. Basados en la construcción de los saberes de enfermería, históricamente determinados por las necesidades comprendidas por la inserción social en el campo de la salud, se consideran los patrones de conocimiento fundamentales en enfermería, así como también, el campo de la actuación y el espacio social de la profesión, para adoptar consideraciones relevantes sobre la formación del ser sociopolítico. Pero, ¿hay, de hecho, espacio para el profesional en este campo de actuación? Se defiende, aquí, la necesidad de que ocupemos los espacios que den margen al reconocimiento de la enfermería como protagonista de la praxis en la salud y en la sociedad.

Descriptores: Enfermería; Conocimiento; Política.

\footnotetext{
${ }^{1}$ Mestranda em Enfermagem pelo Programa de Pós-Graduação da Escola de Enfermagem da Universidade Federal do Rio Grande do Sul. Bolsista CAPES. ${ }^{2}$ Mestranda em Enfermagem pelo Programa de Pós-Graduação da Escola de Enfermagem da Universidade Federal do Rio Grande do Sul. Bolsista CAPES.

${ }^{3}$ Doutora em Educação. Professora Adjunta do Programa de Pós-Graduação da Escola de Enfermagem da Universidade Federal do Rio Grande do Sul.
} 


\section{INTRODUÇÃO}

A enfermagem é uma prática social que responde às exigências definidas pelas organizações das práticas econômicas, políticas, sociais e ideológicas. Essas exigências regulam a prática por dimensionarem o objeto ao qual se aplica, os meios de trabalho que opera, a forma e a destinação dos seus produtos, assim, o conhecimento da enfermagem depende do processo sob o qual ela mesma aconteceu. A partir disso, pode-se abordar questões norteadoras para a compreensão do que é a enfermagem $^{(1)}$.

Esta reflexão parte da construção dos saberes de enfermagem, historicamente determinados pelas necessidades compreendidas pela inserção social no campo da saúde, a fim de avançar em prol da discussão sobre a atuação sócio-política do enfermeiro e a sua importância para o reconhecimento profissional do mesmo.

Esta temática nos interessa por pressupormos a representação social da profissão ainda incipiente, considerando-se o potencial de conhecimento que esta formação prática proporciona. É incômodo reconhecer os limites de uma prática social que parece não ir ao encontro de uma atuação de seres críticos, criativos, conhecedores das mais variadas práticas de saúde, estimulados à competência interpessoal, à gerência e à sensibilidade humana.

O modelo biomédico de atenção à saúde é fator prevalente nas organizações dos serviços de saúde, na assistência prestada e no próprio senso comum. Isto acontece porque o curativismo permanece sendo o foco principal, senão único, na promoção da saúde. Neste contexto, as contribuições da enfermagem acabam sendo sustentações às práticas médicas, constituindo-se de um trabalho complementar na hegemonia médica e assim sendo reconhecido na sociedade. Admirados pela caridade, os profissionais de enfermagem acabam por sustentar, muitas vezes, o mito da doação vocacional como alternativa para garantir prestígio social.

Hoje, as autoras, profissionais participantes da construção do conhecimento na área - o meio acadêmico - entendem que o saber da enfermagem fica limitado a discussões fechadas e, desta forma, perpetua-se o antigo e atual espaço de atuação incumbido e ocupado pelo enfermeiro. Assim, permanece em desconhecimento a riqueza da ampla visão sobre as práticas de saúde, no seu digno significado, a qual o enfermeiro possui pelas competências que adquire no envolvimento íntimo com o indivíduo, enquanto ser de necessidade, seu núcleo social e suas relações com o ambiente. Além disso, a administração dos serviços de saúde proporciona a compreensão sobre o todo no fazer dos diversos profissionais de saúde, permitindo assim, apreender o movimento das ações multifocais em prol da saúde.

Somos profissionais do cuidado, no entanto não estamos atendendo às necessidades de reconhecimento do nosso próprio núcleo sócio-profissional, sendo que, por inúmeras vezes, interpretamos esta questão como problema quando atuamos em prol do cuidado integral. Vimos, por meio deste trabalho, contribuir para o despertar da consciência crítica do profissional em relação à construção cotidiana do fazer, saber e ser, e propor cuidado à profissão do cuidado, pressupondo que este deva iniciar com a busca por um espaço sócio-político que possibilite ao enfermeiro desenvolver seu potencial e, assim, conquistar o prestígio digno à profissão.

\section{CONSIDERAÇÕES SOBRE A CONSTRUÇÃO HISTÓRICO-SOCIAL DO SABER DA ENFERMAGEM}

O saber da enfermagem, determinado pelas características do objeto e pela finalidade do trabalho, é considerado o instrumento que a enfermagem utiliza para realizar o seu trabalho. Este instrumento é legitimado e reproduzido pelo ensino desta prática $^{(2)}$.

Nas primeiras décadas do século XX foram organizadas e sistematizadas as técnicas de enfermagem como estruturas do saber, consideradas como arte de enfermagem. As técnicas, descrição minuciosa da execução de procedimentos de enfermagem e dos materiais necessários para tal, passam a ser parte da área de conhecimento básico dos currículos de enfermagem organizados nos EUA. A arte, como eram denominadas as técnicas, foi considerada o principal conhecimento do ensino de enfermagem.

A prática médica e a de enfermagem passam, então, de independentes a ocuparem o mesmo espaço, e o modelo religioso perde força. Com Florence Nightingale, a disciplina é incorporada pela enfermagem com o intuito de normalizar e regulamentar o meio ambiente do paciente. Na década de 50, o saber de enfermagem procura moldar-se buscando uma fundamentação para as técnicas de enfermagem. Esta fundamentação, chamada científica, embasou-se nas ciências naturais e sociais, e acabou por aproximar-se do saber da medicina e sua autoridade $^{(2)}$. Nos dias atuais, os princípios científicos constituem um saber da enfermagem com presença marcante nos currículos da enfermagem brasileira.

A teoria do objeto da enfermagem, trazida de outras áreas do conhecimento, foi agregada às técnicas de enfermagem, que não possuíam teoria, para construir instrumentos que permitissem aprender o objeto e, assim, possibilitar a dimensão intelectual do trabalho de enfermagem.

O trabalho de gerência da enfermeira, através da administração dita científica, é permitido e estimulado pelo discurso do trabalho de enfermagem realizado em 
Pai DD, Schrank G, Pedro ENR.

equipe ou em grupo, fundamentado por princípios da Escola de Relações Humanas. Desta forma, reitera-se a fragmentação do cuidado, pois a concepção deste acaba pertencendo à enfermeira e a execução aos auxiliares ${ }^{(2)}$.

A procura pela autonomia e especificidade da enfermagem repercute na necessidade de um novo direcionamento para o saber da enfermagem, a construção de um corpo de conhecimentos específicos da enfermagem. As teorias de enfermagem seriam, a partir de então, o instrumento indicado para orientar a enfermagem na busca pela autonomia, delimitando seu campo de atuação ${ }^{(2)}$. As teorias de enfermagem, por sua vez, enfocam essencialmente o paciente e o cuidado, abrangem ambiente, relações cuidado-cuidador e processo saúde-doença.

\section{PADRÕES DE CONHECIMENTO FUNDAMENTAIS EM ENFERMAGEM}

Em 1978, Carper propõe quatro padrões de conhecimento definindo-os como fundamentais à enfermagem. Na década de 90 , estes padrões são explorados e modificados e Jacobs-Kramer e Chinn divulgam, em 1988, um novo modelo de aplicação dos quatro padrões na prática, justificando que as contribuições do passado deveriam ser analisadas no contexto das épocas ${ }^{(3)}$.

Os padrões referiam-se ao Conhecimento Empírico - ciência e metodologia; Ético - conhecimento de normas e códigos éticos, a fim de fornecer suporte a dilemas morais; Pessoal - autoconhecimento para o encontro com o outro; e Estético - arte da percepção, empatia. Assim, como as teorias de enfermagem, os quatro padrões de conhecimento fundamentais à enfermagem atendem necessidades referentes ao cuidado, relação cuidadocuidador e processo saúde-doença.

O quinto padrão de conhecimento, posteriormente elaborado, preocupa-se com a profissão, com a prática de enfermagem no contexto social e as políticas de saúde. Esta proposta é entendida como fundamental para a apreensão de todos os outros modelos, uma vez que se trata do esforço em visualizar a enfermagem no mundo social, político e econômico - a estruturação de relações de poder que afetam resultados de saúde-doença, assim como a enfermagem no planejamento e decisões sobre saúde(3).

Este quinto padrão é entendido como um desafio para a enfermagem porque freqüentemente aceitamos $o$ reconhecimento pela atuação nos momentos de dor, nas crises e nos momentos de intimidade, situações nas quais o paciente encontra-se perturbado. No entanto, aceitamos o esquecimento do ser (paciente) politicamente capaz, uma vez que não somos reconhecidos por contribuições para a construção, decisão e planejamento, de diretrizes políticas à saúde.

O padrão de conhecimento sócio-político permite adotarmos uma postura crítica sobre o contexto da nossa prática em prol do futuro da saúde e da profissão. Embora tenha esta relevância, por vezes este padrão não é considerado nas reflexões críticas sobre o conhecimento da enfermagem. Isto pode ser constatado em discursos ${ }^{(4)}$ que não incluem o conhecimento (e, portanto, também a atuação) sócio-político do enfermeiro, mesmo nos casos em que a discussão volta-se à totalidade na formação do ser enfermeiro.

\section{A ATUAÇÃO DA ENFERMAGEM E O ESPAÇO SOCIAL DA PROFISSÃO}

O trabalho da enfermagem, localizado na interface dos outros trabalhos em saúde, possui características que o identificam, assim como a seus trabalhadores, tais como a forma como os seus saberes estão constituídos, seus instrumentos e seus objetos de trabalho, suas formas de organização e submissão e seus movimentos no espaço e tempo do plantão. A realidade do trabalho em saúde e em enfermagem (re)configura essas características. Desta forma, é no próprio cotidiano do trabalho que a identidade do enfermeiro é construída, através de mediações do ser em seu mundo cotidiano de trabalho ${ }^{(6)}$.

O processo de trabalho da enfermagem na produção de cuidados de saúde no modelo clínico tem sua direção atribuída ao projeto intelectual ${ }^{(7)}$. Assim, o modo como o trabalho é realizado, as relações que se dão entre os homens no trabalho, e como a produção de cuidados se estrutura, estão sob orientação do modelo clínico que articula os atores deste cenário em torno da atuação médica.

Embora muito se tenha discutido sobre a importância do trabalho interdisciplinar da equipe de saúde para a construção de um modelo centrado no paciente a fim de nortear o planejamento e a execução das ações de saúde, encontramos uma realidade organizada em função do diagnóstico e terapêutica de corpos doentes. Desde 1986, com a Carta de Otawa, o conceito de saúde extrapola o corpo físico, sendo ampliado de modo a considerar o contexto social, ambiental, político e econômico.

Porém, as práticas cotidianas em saúde continuam prestando uma assistência em prol da queixa-conduta. Nesse sentido, a atuação da enfermagem acompanha a evolução do setor saúde, uma vez que, continua realizando seu trabalho em decorrência da clínica do corpo, da qual o médico é o protagonista.

$\mathrm{O}$ que pode ser observado junto ao processo de trabalho da enfermagem hospitalar é a liberdade de ação da enfermeira, construída na relação de interdependência com os profissionais de saúde. Além disso, a prática de cuidar e a de gerenciar são dimensões modificáveis 
conforme a especificidade das atividades realizadas pelas enfermeiras nas diferentes unidades especializadas ${ }^{(8)}$.

Ainda na atualidade, constata-se uma idealização da caridade no trabalho da enfermeira por meio da forte presença de mitos da profissão. Essa idealização chocase com a concretude exigida pelo modelo clínico, no qual seus elementos estruturais inviabilizam essa associação ${ }^{(8)}$.

Estudos realizados pela enfermagem ${ }^{(6,9-12)}$ e o próprio Ministério da Saúde ${ }^{(13)}$, reconhecem a necessidade de espaços no local de trabalho para a materialização das potencialidades do ser trabalhador. Estes são resultados de olhares voltados às classes dominadas, uma vez que as relações de poder sempre marcaram o trabalho em saúde.

O trabalho da enfermagem brasileira acontece, muitas vezes, sob condições precárias de recursos humanos e materiais, baixos salários, ambiente insalubre, dividido por tarefas e com extensas horas dedicadas ao trabalho que, na maioria das vezes, não oferece sequer local apropriado ao descanso. Onde estão os protagonistas desta cena? Estariam alienados ao trabalho, à sua saúde e à qualidade do serviço prestado?

Quanto ao poder, a interdependência e a complementaridade no trabalho hospitalar da enfermagem, pode-se dizer que a enfermeira está menos 'armada' para as disputas de espaço e para a consolidação do seu saber. Majoritariamente mulheres, as enfermeiras universitárias e a enfermagem atestam as nuances de gênero que estruturam a divisão sexual e as relações de trabalho na saúde. A divisão sexual do trabalho se exprime no trabalho de enfermagem e no trabalho hospitalar de uma forma geral. As relações hierárquicas, a segregação dos serviços, de postos e funções, atestam que o setor hospitalar soube tirar proveito das 'qualidades' femininas ${ }^{(14)}$.

Desta forma, a atuação da enfermagem, bem como o espaço social da profissão, têm implicações de gênero na consolidação de práticas subjetivadas atestando a divisão sexual do trabalho no campo da saúde.

A interdisciplinaridade da equipe para a promoção da saúde tem sido uma questão de investimentos nas atuais estratégias de implementação do Programa de Saúde da Família, o que mostra o reconhecimento dos saberes de diferentes profissionais a fim de promover saúde de forma integral. As estratégias do programa pressupõem que a saúde esteja voltada à comunidade, interagindo de forma coletiva a fim de promover a eqüidade, universalidade e a integralidade. Permeando estes princípios, que balizam o Sistema Único de Saúde, encontramos as propostas de humanização da assistência através do acolhimento e da participação social. É na realização destas ações que o enfermeiro põe em prática um saber que contempla no modelo de saúde as relações sociais do indivíduo e do mesmo com o ambiente. Assim, o enfermeiro legitima seu saber, e isso inquieta àqueles que sempre detinham o saber determinante para as práticas dos outros profissionais de saúde. Porém, mesmo neste campo de atuação, a organização do trabalho em saúde ainda encontra-se na dependência do horário da consulta médica e da medicalização da doença. A enfermagem como prática social, por sua vez, atende às exigências assim definidas, reproduzindo ações complementares à prática médica.

Diante disto, acrescentam-se ainda as diferenças salariais que colocam a enfermagem em desvantagens na luta pela representatividade da classe em espaços de poder. Esta situação, no entanto, não repercute em verdadeiras ações em prol do desejo de mudança desta realidade.

\section{A FORMAÇÃO DO SER SÓCIO-POLÍTICO}

As reformas curriculares do ensino de enfermagem têm procurado considerar as demandas do mercado de trabalho e transformações ocorridas no setor saúde como desafios na formação de marcos referenciais e conceituais de seus currículos. Para tal, espaços de construção e circulação de saberes emergem no ambiente acadêmico, o que possibilita a transversalidade do conhecimento em prol da globalização, elemento determinante deste processo $^{(15-17)}$.

No entanto, deve-se considerar insuficiente almejar um conhecimento que apenas permita ao profissional equiparidade na concorrência do mercado de trabalho. Além disso, precisa-se construir uma formação criadora de identidade e representatividade visível às diversas esferas sociais e, desta forma, alcançar o reconhecimento da profissão e reconstruir as exigências sociais que nos sustentam, participando das organizações das políticas de saúde e construindo o processo de ser enfermagem.

Pensa-se como uma possibilidade de mudança a avaliação dos discursos acadêmicos, uma vez que estes constróem, também, subjetivamente, modos de ser. O planejamento das ações pedagógicas deve, portanto, privilegiar a formação com base em prioridades pautadas na busca por reconhecimento como uma necessidade.

O ensino é um momento privilegiado de construção do saber a fim de estimular a consolidação de um corpo de conhecimento próprio da enfermagem, repercutindo na identidade do enfermeiro ${ }^{(18)}$. Este, em nossa opinião, potencializa-se através de práticas discursivas que consolidem um paradigma inovador no sentido de formar profissionais instigados à participação política que possibilite a visibilidade do corpo de conhecimento produzido pela enfermagem, assim como da identidade do profissional atuante em defesa da vida.

Atualmente, o profissional de enfermagem deve ser capaz de compreender e participar de decisões mais complexas e interagir socialmente, mobilizando um saber construído na interação do indivíduo com a situação. Esse saber significa ter uma visão globalizada colocando, na 
prática, fragmentos de diferentes especialidades combinadas com a própria experiência.

O saber da enfermagem está no exercício das atividades, no qual os profissionais devem relacionar os conhecimentos conceituais adquiridos com os problemas e acontecimentos encontrados em situações concretas. Assim, o enfermeiro estará atuando criticamente, rompendo com as delimitações impostas e tornando visível as suas competências.

$\mathrm{Na}$ construção de projetos político-pedagógicos na enfermagem, deve-se incluir à educação profissional o desenvolvimento de atitudes críticas e reflexivas e o conhecimento para praticar a interdisciplinaridade. A enfermagem, no contexto da área da saúde, espelha o resultado das políticas sociais e econômicas nacionais e internacionais. Sendo assim, é produto de interesses diversos no espaço político, o qual não é um campo neutro, é um campo do saber, portanto local de disputa de relações de poder ${ }^{(19)}$. Desta forma, lidar com a relação saber-poder torna-se um desafio a fim de que possamos "explicitar a enfermagem" frente às políticas de saúde e de educação com comprometimento social, participando do planejamento e não somente da execução de ações.

O impacto que ocorre na transição da academia para a atividade profissional poderia ser diminuído se, durante a formação, os alunos desenvolvessem um pensamento crítico, participativo e transversal das diversas áreas do saber, participando de atividades acadêmicas que envolvam questões sócio-políticas. Desta forma, o futuro profissional já estaria desperto para uma postura crítica sobre o contexto da enfermagem no mundo e do mundo da enfermagem.

Além do compromisso dos futuros profissionais de enfermagem com uma atenção à saúde mais justa, igualitária e de melhor qualidade, os formadores destes profissionais também devem estar inseridos nesse contexto, realizando uma prática coerente com o discurso, concretizando diretrizes curriculares comprometidas também com o futuro da profissão. Portanto, pertence também aos formadores a tarefa de relacionar saberes, práticas e as conseqüências da profissão para a saúde, para a qualidade de vida e, principalmente, para o desenvolvimento de uma prática sócio-política, refletindo sobre a teoria e a prática, compreendendo-as de modo desafiador na busca pela criticidade e criatividade do enfermeiro como ser participante na estruturação social e política das práticas de saúde.

\section{CONSIDERAÇÕES FINAIS}

O conhecimento da enfermagem provém de uma visão ampla e abrangente sobre saúde, transcendente às práticas médico-hospitalares. O caráter dessa profissão, às vezes convergente, múltiplo, heterogêneo, conflitivo, ambivalente, afetivo e socialmente relevante, projeta uma infinidade de competências sócio-políticas. Esta situação reflete sua singularidade e a preocupação dos seus atores que buscam conhecimentos nos diversos níveis de sua atuação social.

Para o direcionamento da enfermagem, além do ensino e da pesquisa, considera-se importante a organização política da profissão, uma vez que, por meio do fortalecimento desta, alcançar-se-á uma representatividade social importante e, talvez, um novo paradigma na prática discursiva a respeito da atuação do profissional enfermeiro, assim como, na abrangência do seu saber.

Adotar uma postura crítica frente ao contexto da prática significa, também, pensar em transformações. Acredita-se na relevância destas, principalmente em relação aos discursos que orientam objetiva e subjetivamente a formação profissional, uma vez que a enfermagem parece estar ausente nas posições de poder que garantem as decisões sociais, sendo que dentre estas, é imprescindível que o enfermeiro atue nas relacionadas à saúde.

Diante destas colocações, surgem indagações relativas à atuação sócio-política do enfermeiro. Há, de fato, espaço para o profissional neste campo de atuação? Será que podemos afirmar que não existem espaços para estes profissionais? Ou estariam alheios ao que está posto, distanciando-se de um compromisso e responsabilidade que criassem condições de assumir e demonstrar a capacidade crítico-reflexiva-criativa em prol da saúde da população?

Será, ainda, não dar visibilidade à profissão uma forma de escamotear a vontade do enfermeiro em aprofundar a sua capacidade cognitiva e de transformação de sua prática? Essas e outras tantas questões nos inquietam e nos fazem refletir sobre o nosso papel no contexto de todo o processo saúde-doença, ensino-aprendizagem, individual-coletivo, público-privado, entre outros.

O desejo que aqui expomos é o de construirmos, coletivamente, uma profissão mais atuante, comprometida, participante das instâncias decisórias das políticas públicas, sociais e institucionais. O primeiro passo a ser dado, talvez o principal e mais desafiador, seja a mudança paradigmática na formação do profissional enfermeiro para que possamos construir uma profissão mais atuante ${ }^{(19)}$, com o compromisso social necessário para que busquemos conquistar esferas de decisão a fim de realmente atuarmos em defesa da vida, e mais do que isso, possibilitar espaços que dêem visibilidade à profissão, garantindo assim a chance de novas margens à imagem da enfermagem perante a sociedade.

\section{REFERÊNCIAS}

1. Kirchhof ALC. O trabalho da enfermagem: análise e perspectivas. Rev Bras Enferm. 2003; 56(6):669-73. 
2. Almeida MCP, Rocha JSY. O saber de enfermagem e sua dimensão prática. São Paulo: Cortez; 1986.

3. White J. Patterns of knowing: review, critique, and update. ANS Adv Nurs Sci. 1995; 17(4):73-86. Review.

4. Ferreira HM. A totalidade do conhecimento da enfermagem: uma abordagem curricular. Acta Paul Enferm. 2003; 16(1):56-65.

5. Cestari ME. Padrões de conhecimento da enfermagem e suas implicações no ensino. Rev Gaúch Enferm. 2003; 24(1):34-42.

6. Netto LFSA, Ramos FRS. Considerações sobre o processo de construção da identidade do enfermeiro no cotidiano de trabalho. Rev Lat Am Enferm. 2004; 12(1):50-7.

7. Lima MADS, Almeida MCP. O trabalho de enfermagem na produção de cuidados de saúde no modelo clínico. Rev Gaúch Enferm. 1999; 20 (n. especial):86-101.

8. Gustavo AS, Lima MADS. Idealização e realidade no trabalho da enfermeira em unidades especializadas. Rev Bras Enfermagem. 2003; 56(1):24-7.

9. Oliveira BRG, Collet N. Relações de poderes (inter)profissionais e (inter)institucionais no hospital. Rev Bras Enferm. 2000; 53(2):295-300.

10. Gomes ES, Anselmo MEO, Lunardi Filho WD. As reuniões de equipe como elemento fundamental na organização do trabalho. Rev Bras Enferm. 2000; 53(3):472-80.

11. Gelbcke FL, Leopardi MT. Perspectivas para um novo modelo de organização do trabalho da enfermagem. Rev Bras Enferm. 2004; 57(2):193-7.

12. Matos E, Pires D. A organização do trabalho da enfermagem na perspectiva dos trabalhadores de um Hospital Escola. Texto \& Contexto Enfermagem. 2002; 11(1):187-205.

13. Brasil. Ministério da Saúde. Secretaria Executiva. Núcleo Técnico da Política Nacional de Humanização. HumanizaSUS: política nacional de humanização: documento base para gestores e trabalhadores do SUS. Brasília: Ministério da Saúde; 2004. 57 p. (Textos Básicos de Saúde, Série B).

14. Lopes MJM. Poder, interdependência e complementaridade no trabalho hospitalar: uma análise a partir da enferm. Rev Bras Enfermagem. 1997; 50(3):381-90.

15. Nascimento ES, Santos GF, Caldeira VP, Teixeira VMN. Formação por competência do enfermeiro: alternância teoria-prática, profissionalização e pensamento complexo. Rev Bras Enferm. 2003; 56(4):447-52.

16. Barbosa MA, Brasil VV, Sousa ALL, Monego ET. Refletindo sobre o desafio da formação do profissional de saúde. Rev Bras Enferm. 2003; 56(5):574-6.

17. Witt RR, Almeida MCP. Competências dos profissionais de saúde no referencial das funções essenciais de saúde pública: contribuição para a construção de projetos pedagógicos na enfermagem. Rev Bras Enferm. 2003; 56(4):433-8.

18. Stedile NLR. Ensino de enfermagem: momento privilegiado de construção do conhecimento. Acta Paul Enferm. 2002; 15(3):79-86.

19. Brêtas ACP. O(a) enfermeiro(a) e a política: questões para reflexão. [editorial]. Acta Paul Enferm. 2003; 16(2):5. 